\title{
Enhancement of PAC addition for MBR treating micro-polluted water resource loading with 2,4,6-TCP
}

\author{
Quan ZHANG ${ }^{1, a}$, Wenyi DONG ${ }^{2, b}$, Lei LIU ${ }^{3, c}$, Rubing HAN ${ }^{2, d}$
}

1 Harbin Institute of Technology, School of Municipal and Environmental Engineering, Harbin, 150090.

2 Harbin Institute of Technology Shenzhen Graduate School, Shenzhen, China, 518055.

3 Quality Testing Center, Shenzhen, China, 518055

aemail: granthillquan@163.com, bemail:694093630@qq.com, cemail: ‘email: lyc072105@126.com,

demail : 501714771@qq.com.

Keywords: MBR; 2,4,6-Trichlorophenol; Micro-pollutant water resource; Powered activated carbon

\begin{abstract}
In this investigation, the removals of pollutants especially 2,4,6-trichlorophenol by MBR and a simultaneous application of powdered activated carbon with MBR using flat sheet membrane were contrasted. The results displayed that both the two systems could effectively remove ammonia-N, total organics and turbidity while PAC-MBR had higher removal efficiency. For 2,4,6-TCP, MBR process had stable removal efficiency of $77 \%$ while PAC-MBR could remove 2,4,6-TCP by $91 \%$ on average. Furthermore, PAC-MBR had much higher maximum 2,4,6-TCP removal capability which could deal with raw water loading $5567 \mu \mathrm{g} / \mathrm{L} \mathrm{2,4,6-TCP.} \mathrm{Therefore,} \mathrm{PAC}$ addition is a simple and effective strategy to treat micro-polluted water resource.
\end{abstract}

\section{Introduction}

The application of membrane bioreactor (MBR) technology in drinking water treatment has gained unprecedented in recent years due to the good performance in organic matters removal [1]. In MBR system, ultrafiltration is substituted for the traditional separation unit which led to better retention performance of particulates and sludge. As a result, longer retention time of activated sludge and microbes is obtained as well as improvement of contaminants removal capability [2]. Owing to combine with biological degradation process of activated sludge MBR could effectively remove ammonia and natural organic matters [3]. However, due to the discharge of industrial wastewater and domestic sewage without effective treatment, synthetic organic compounds (SOCs) with strong toxicity was found in the surface water resource around or inside urban agglomeration which was not easily eliminated even in MBR process [4,5].

In order to acquire enhancement of water purification and performance stability of MBR, adsorption material such as powdered activated carbon is added to MBR in applications and studies, and good results are achieved $[6,7,8]$. Exceptional adsorption performance of organics by activated carbon is proved as well as the natural organic matters removal enhancement by PAC which was believed to be the major function of PAC addition in organics removals [5,9]. In fact, the additional PAC in MBR reactor also provides an enormous specific surface for bacterial attachments [10].

In this study, 2,4,6-trichlorophenol (2,4,6-TCP) one of potential water pollutants widely used in the preparation of biocides and flame retardants was selected as the target synthetic organic compound $[11,12]$. MBR with and without PAC addition were operated to treat real micro-polluted surface water. The mechanisms of PAC for 2,4,6-TCP removal enhancement were also discussed.

\section{Materials and methods}

Two identical laboratory-scale submerged MBR, with working volume of $3.0 \mathrm{~L}$ were operated side by side to investigate the water resource treatment The operational conditions were kept the same except that one reactor was added with the PAC for pollutant removal enhancement. A 0.08 
$\mu$ m plat-sheet poly vinylidene fluoride (PVDF) ultra-filtration (UF) membrane (Peier, China) was immersed in the MBR. A suction pump (BT100-2J, Longer, China) was used to withdraw the effluent through the membrane at a filtration-to-idle cleaning ratio of $8 \mathrm{~min}: 2 \mathrm{~min}$. Aeration was provided at the bottom of the reactor for DO supplement and continuous membrane cleaning. The MBR was operated in the constant flux mode, the trans-membrane pressure (TMP) was monitored with a manometer in mmHg. A constant hydraulic retention time (HRT) of 1.5 hours was kept throughout the experimental phase. PAC was intermittently (2 times/d) injected into the bioreactor of PAC-MBR at a dosage of $5 \mathrm{mg} / \mathrm{L}$ influent. Both the two MBRs were sampled in terms of influent, bulk solution and effluent intermittently for pollutants analysis. Furthermore, the effluent was stored in an effluent tank to obtain the average of pollutants in $12 \mathrm{hr}$ effluent.

The 2,4,6-TCP adsorption capacities of activated sludge in MBR and PAC-sludge in PAC-MBR were tested by the same method following: The samples collected from MBR and PAC-MBR were washed with DDW for several times until no 2,4,6-TCP was determined out in the bath. On the other hand, the 2,4,6-TCP was dissolved into pure water and aerated with pure nitrogen $\left(\mathrm{N}_{2}\right)$ in order to substitute oxygen to decrease the DO concentration to less than $0.2 \mathrm{mg} / \mathrm{L}$. More than $20 \mathrm{~m}$ $\mathrm{mol} / \mathrm{L}$ sodium azide was also dosed into the solution to inhibit microbial activity for trance-organic biodegradation. The mixture of sludge sample and 2,4,6-TCP solution was then stirred in condition of $25^{\circ} \mathrm{C}$. The 2,4,6-TCP concentrations of the mixture were determined for the calculations and comparisons.

\section{Results and discussion}

Impurities removal efficiencies of MBR and PAC-MBR were summarized and listed in Table 1. During the operations of MBR and PAC-MBR, ammonia-N reduction through biological process was observed, accounting for the ammonia-N removal efficiencies of $68.4 \%$ and $78.2 \%$, respectively. Whereas the influent had ammonia-N of $1.52 \pm 0.38 \mathrm{mg} / \mathrm{L}, \mathrm{MBR}$ had ammonia-N of $0.48 \pm 0.22 \mathrm{mg} / \mathrm{L}$ in effluent which was sometimes substandard. On the other hand, PAC-MBR was able to reduce ammonia- $\mathrm{N}$ concentration to $0.34 \mathrm{mg} / \mathrm{L}$ on average, which was qualified.

Organic matters in water resource could be well estimated in terms of TOC and $\mathrm{UV}_{254}$. As showed in the table, during the experimental period, the MBR was able to reduce TOC from $3.95 \pm 0.97 \mathrm{mg} / \mathrm{L}$ in raw water to $2.07 \mathrm{mg} / \mathrm{L}$ in effluent on average, i.e. $45.6 \%$ of organic matters were removed which was as high as mentioned in Patsios' paper [13].Meanwhile, an even higher TOC removal efficiency was obtained in PAC-MBR system that the average removal rate reached $63.1 \%$ which meant effluent had average TOC concentration of $1.42 \mathrm{mg} / \mathrm{L}$ when the same fed with MBR was in raw water. Owing to fluctuation of water quality caused by waste water and rainwater import, the $\mathrm{UV}_{254}$ of raw water in this investigation was $0.086 \pm 0.052 \mathrm{~cm}^{-1}$. The MBR effluent had $\mathrm{UV}_{254}$ of $0.051 \pm 0.016$ i.e. removal rate of $40.7 \pm 18.6 \%$. It was noted that PAC has an unsaturated bond or negative charge fraction favoring the aromatic compounds removal through adsorption way. During the operation, PAC-MBR had a good adaptability for raw water of various organic matters that the $\mathrm{UV}_{254}$ was reduced to $0.034 \mathrm{~cm}^{-1}$ that PAC addition caused $19.8 \%$ improvement of $\mathrm{UV}_{254}$ removal rate.

Turbidity was reduced from $8.82 \pm 3.56$ NTU in raw water to $0.12 \pm 0.11$ NTU in MBR effluent and $0.08 \pm 0.05$ in PAC-MBR effluent. Due to the high particulate matters and colloids retention efficiency of ultrafiltration membrane, the pollutants formed turbidity was almost retained in the MBR tank and separated with effluent which led to turbidity removal as high as $98.6 \%$. Furthermore, the PAC addition further improved turbidity removal efficiency.

AOC elimination was also studied and compared in this investigation considering the microbial risk. In a study by Chu, MBR removed AOC from $134.5 \pm 52.7$ to $25.3 \pm 19.9 \mu \mathrm{g} / \mathrm{L}$ in the biological way [14]. The comparable efficiency was also obtained in this investigation that MBR and PAC-MBR decreased AOC from $115 \mu \mathrm{g} / \mathrm{L}$ in raw to 42 and $35 \mu \mathrm{g} / \mathrm{L}$ in effluent, respectively, which meant the biostability of the finishing water was improved. 
Table 1 Pollutants removal efficiencies of MBR and PAC-MBR

\begin{tabular}{cccccc}
\hline \multirow{2}{*}{ Water quality indexes } & \multirow{2}{*}{ Raw water } & \multicolumn{2}{c}{ MBR } & \multicolumn{2}{c}{ PAC-MBR } \\
\cline { 3 - 6 } & & Effluent & Removal (\%) & Effluent & Removal (\%) \\
\hline TOC (mg/L) & $3.95 \pm 0.97$ & $2.07 \pm 0.88$ & $45.6 \pm 22.9$ & $1.42 \pm 0.53$ & $63.1 \pm 13.8$ \\
$\mathrm{UV}_{254}\left(\mathrm{~cm}^{-1}\right)$ & $0.086 \pm 0.052$ & $0.051 \pm 0.016$ & $40.7 \pm 18.6$ & $0.034 \pm 0.013$ & $60.5 \pm 15.1$ \\
Ammonia-N (mg/L) & $1.52 \pm 0.38$ & $0.48 \pm 0.22$ & $68.4 \pm 14.5$ & $0.34 \pm 0.16$ & $77.6 \pm 22.4$ \\
Turbidity (NTU) & $8.82 \pm 3.56$ & $0.12 \pm 0.11$ & $98.6 \pm 1.2$ & $0.08 \pm 0.05$ & $99.1 \pm 0.6$ \\
AOC $(\mu \mathrm{g} / \mathrm{L})$ & $115 \pm 26$ & $42 \pm 15$ & $63.5 \pm 13.0$ & $35 \pm 12$ & $69.6 \pm 10.4$ \\
\hline
\end{tabular}

For TOC, $\mathrm{UV}_{254}$, Ammonia-N and turbidity $n=25$; for AOC, $n=5$.

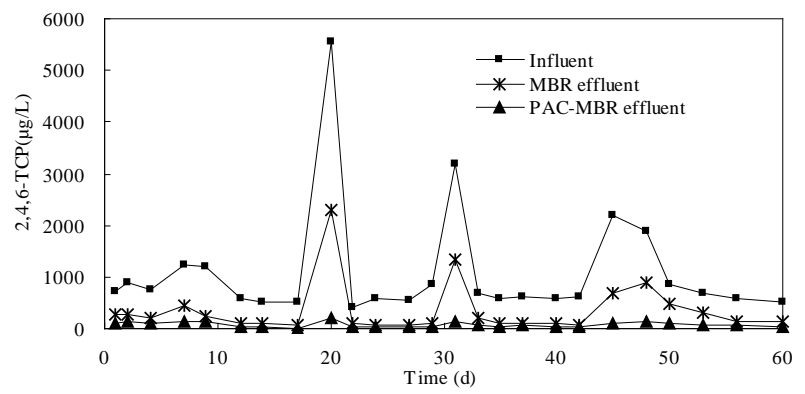

Fig.1. Comparison of 2,4,6-TCP removal by MBR and PAC-MBR

In this investigation, 2,4,6-TCP was employed as the target synthetic organic in micro-polluted water resource due to the frequently found in surface water. Furthermore, the effective removal of trace organics organic compounds represented by TCP was of great significance for drinking water treatment. As illustrated in Fig. 1, both MBR and PAC-MBR had acceptable 2,4,6-TCP removal efficiencies in the operation. Normally, the 2,4,6-TCP concentration in raw water was controlled at 500 to $800 \mu \mathrm{g} / \mathrm{L}$ in order to investigate the general 2,4,6-TCP removal performances of the two MBRs. Herein the MBR could reduce 2,4,6-TCP from $637 \mu \mathrm{g} / \mathrm{L}$ to $151 \mu \mathrm{g} / \mathrm{L}$ on average i.e. removal rate of $77 \%$ without PAC addition was obtained when no more than $800 \mu \mathrm{g} / \mathrm{L} 2,4,6-\mathrm{TCP}$ was in raw water during the whole operation. Meanwhile, PAC-MBR had higher 2,4,6-TCP removal efficiency that the average removal rate was $91 \%$ in condition of less than $800 \mu \mathrm{g} / \mathrm{L} \mathrm{2,4,6-TCP}$ was in raw water. In contrast, the additional PAC increased removal rate by $14 \%$ which led to much lower 2,4,6-TCP concentration in effluent that only $56.8 \mu \mathrm{g} / \mathrm{L}$ on average during the operation.

On day 31, influent loaded with high 2,4,6-TCP concentration of $3175 \mu \mathrm{g} / \mathrm{L}$ was pumped into the reactors. Still, PAC-MBR reduced 2,4,6-TCP to $142 \mu \mathrm{g} / \mathrm{L}$ while MBR effluent contained $1325 \mu \mathrm{g} / \mathrm{L}$ of 2,4,6-TCP. The different performance confirmed the positive effects of PAC addition to MBR system[15].

In MBR system, there were two fundamental effects contributing to the reduction of 2,4,6-TCP, i.e. (i) biodegradation by microbes; (ii) adsorption by activated sludge [16]. In PAC-MBR, the additional PAC also increased the MBR performance by enhancements of adsorption and biodegradation capabilities. Fig. 2 a illustrated the contributions of adsorption processes for 2,4,6-TCP removal in MBR and PAC-MBR. Due to the lack of suspended solids and poor adsorption capacity of sludge, in MBR system, adsorption process could only remove 2,4,6-TCP by $2 \mu \mathrm{g} / \mathrm{L}$ on average during the whole operation. In contrast, the PAC-sludge in PAC-MBR tank had much higher 2,4,6-TCP adsorption capacity as well as MLSS. As a result, $C_{a d}$ of $40 \mu \mathrm{g} / \mathrm{L}$ on average was obtained. Therefore, the PAC addition provided 2,4,6-TCP adsorption enhancement by $8 \mu \mathrm{g}$ 2,4,6-TCP /mg PAC.

In order to compare the 2,4,6-TCP biodegradation performances in MBR and PAC-MBR, $C_{b i o}$ was calculated and showed in Fig 2 b. It was obvious that biodegradation process made much more contribution for 2,4,6-TCP removal than adsorption in both MBR and PAC-MBR. Thus, $466.7 \mu \mathrm{g} / \mathrm{L}$ of 2,4,6-TCP was eliminated by biodegradation in MBR process while PAC-MBR had higher 2,4,6-TCP biodegradation capacity that $481.1 \mu \mathrm{g} / \mathrm{L}$ of 2,4,6-TCP was reduced by biodegradation. The enhancement of 2,4,6-TCP biodegradation capability was believed to be caused by PAC 
addition. Under the combinative enhancement of biodegradation and adsorption caused by PAC, PAC-MBR was able to reduce $52.6 \mu \mathrm{g} / \mathrm{L}$ 2,4,6-TCP more than MBR.
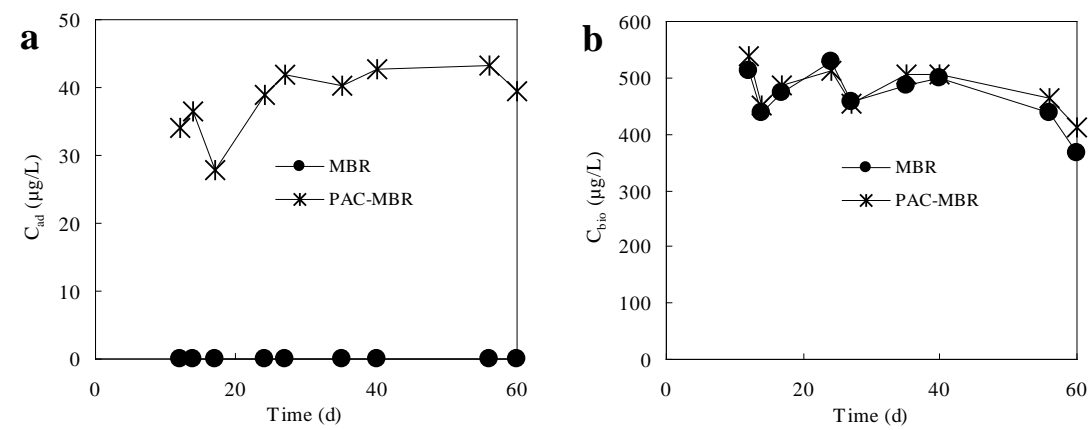

Fig. 2. Comparison of $\mathrm{C}_{\mathrm{ad}}$ (a) and $\mathrm{C}_{\mathrm{bio}}$ (b) of MBR and PAC-MBR

In operations of MBR and PAC-MBR, SRT was amounting to 30 days without expert sludge discharge except wastage in samples of bulk mixture. In the experimental raw water, particulate matters and biodegradable organic compounds were rare which led to low concentration of MLSS in MBR. In PAC-MBR, due to the dosage of PAC the MLSS reached much higher level compared with the MBR, as shown in Fig.3 a. During the stable phase of MBR and PAC-MBR operation, the average MLSS was 0.55 and $3.18 \mathrm{~g} / \mathrm{L}$, respectively.

Due to the high specific surface area of PAC for bacterial attachments, biomass could growth well with high activity in PAC-MBR [17]. As shown in Fig. 3 b, PAC-MBR had higher lipid-P concentration in bulk solution. On average MBR had average lipid-P concentration of $12.99 \mathrm{n}$ mol $\mathrm{P} / \mathrm{ml}$ while PAC-MBR had lipid-P of $22.46 \mathrm{n} \mathrm{mol} \mathrm{P} / \mathrm{ml}$. The divergence of microbes was assumed the cause of different biodegradation capacity of the two systems.
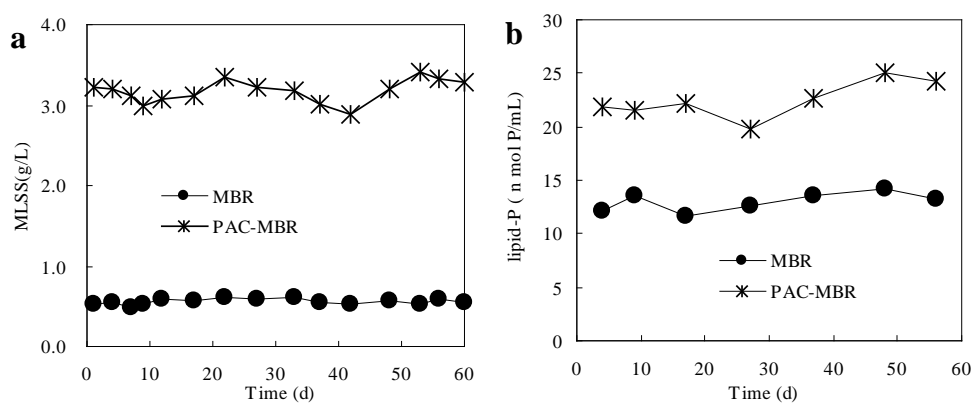

Fig. 3. Comparison of MLSS (a) and lipid-P in bulk solution (b)

\section{Conclusion}

In this study, comparison of the pollutants removal efficiencies especially the removals of 2,4,6-TCP in the MBR and PAC-MBR systems were investigated. The MBR system was able to reduce TOC concentration from $4.0 \mathrm{mg} / \mathrm{L}$ in raw water to $2.0 \mathrm{mg} / \mathrm{L}$ in effluent while PAC-MBR performed better total organics removal efficiency that higher and more stable TOC removal rate was obtained. Furthermore, the PAC addition was able to further decline $\mathrm{UV}_{254}$, AOC and THMs.

The PAC-MBR showed higher 2,4,6-TCP removal rate than MBR individual by $14 \%$ in the operation. The PAC enhancement for 2,4,6-TCP removal efficiency was proved caused by adsorption capacity providing and biomass increasing. The PAC addition also improved the microbial activity of MBR bulk solution. Due to the combination of excellent biodegradation capability and adsorption capacity of PAC accumulation, the PAC-MBR could effectively treat with influent loading with $5.5 \mathrm{mg} / \mathrm{L}$ 2,4,6-TCP.

\section{References}

1 Tian J.Y.,. Chen Z.L, Yang Y.L., Liang H., Nan J., Wang Z.Z., Li G.B. (2009) Hybrid process of 
BAC and sMBR for treating polluted raw water. Bioresource Technology. 100: 6243-6249.

2 Fiksdal L., Leiknes T. (2006) The effect of coagulation with MF/UF membrane filtration for the removal of virus in drinking water. Journal of Membrane Science. 279: 364-371.

3 Nuhoglu A., Pekdemir T., Yildiz E., Keskinler, B. Akay G. (2008) Drinking water denitrification by a membrane bio-reactor. Water Research. 38 (14-15): 3225-3232.

4 Bach C., Dauchy X., Chagnon M.C., Etienne S. (2012)Chemical compounds and toxicological assessments of drinking water stored in polyethylene terephthalate (PET) bottles: A source of controversy reviewed. Water Research. 46: 571-583.

5 Sagbo O., Sun Y.X., Hao A.L., Gu P. (2008) Effect of PAC addition on MBR process for drinking water treatment. Separation and Purification Technology. 58:320-327.

6 Nguyen L.N., Hai F.I., Kang J., Nghiem L.D., Price W.E., Guo W., Ngo H.H., Tung K.L. (2013) Comparison between sequential and simultaneous application of activated carbon with membrane bioreactor for trace organic contaminant removal. Bioresource Technology. 130: 412-417.

7 Zhao Y., Gu P. (2006) Effect of powdered activated carbon dosage on retarding membrane fouling in MBR. Separation and Purification Technology. 52: 154-160.

8 Hai F.I., Tessmer K., Nguyen L.N., Kang J., Price W.E., Nghiem L.D. (2011) Removal of micro-pollutants by membrane bioreactor under temperature variation. Journal of Membrane Science. 383: 144-151.

9 Sang J.Q., Zhang X.H., Li L.Z., Wang Z.S. (2003) Improvement of organics removal by bio-ceramic filtration of raw water with addition of phosphorus. Water Research. 37: 4711-4718.

10 Khan M.T., Lewandowski Z., Takizawa S., Yamada K., Katayama H., Yamamoto K., Ohgaki S. (2009) Continuous and efficient removal of THMs from river water using MF membrane combined with high dose of PAC. Desalination. 249: 713-720.

11 Gaitan I.J., Medina S., Gonzalez J.C., Rodriguez-Lopez E. A., Espejo A.J., Osma J.F., Sarria V.,. Alméciga-Díaz C.J, Sánchez O.F. (2011) Evaluation of toxicity and degradation of a chlorophenol mixture by the laccase produced by Trametes pubescens. Bioresource Technology. 102: 3632-3635.

12 M.Belchik S., Schaeffer S., Hasenoehrl S., Xun L. (2010) A b-barrel outer membrane protein (2,4,6-TCPY) facilitates cellular uptake of polychlorophenols in the gram negative bacterium Cupriavidus necator. Biodegradation. 21: 431-439.

13 Patsios S.I., Karabelas A.J. (2011) An investigation of the long-term filtration performance of a membrane bioreactor (MBR): The role of specific organic fractions. Journal of Membrane Science. 372:102-115.

14 Chu L.B., Li S.P. (2006) Filtration capability and operational characteristics of dynamic membrane bioreactor for municipal wastewater treatment. Separation and Purification Technology. 51: 173-179.

15 Krishnaiah D., Anisuzzaman S.M., Bono A., Sarbatly R. (2013) Adsorption of 2,4,6-trichlorophenol (TCP) onto activated carbon. Journal of King Saud University-Science.25(3): 251-255.

16 Tian J.Y., Liang H., Yang Y.L., Tian S., Li G.B. (2008) Membrane adsorption bioreactor (MABR) for treating slightly polluted surface water supplies: As compared to membrane bioreactor (MBR). Journal of Membrane Science. 325:262-270.

17 Lesage N., Sperandio M., Cabassud C. (2008) Study of a hybrid process: adsorption on activated carbon/membrane bioreactor for the treatment of an industrial wastewater. Chem. Eng. Process. 47: 303-307. 